\title{
Hydrodynamic water tunnel for characterization of hydrokinetic microturbines designs
}

\author{
Eduardo Álvarez-Álvarez ${ }^{1}$ (1) - Manuel Rico-Secades ${ }^{2} \cdot$ Aitor Fernández-Jiménez $^{1} \cdot$ Rodolfo Espina-Valdés $^{1}$. \\ E. L. Corominas ${ }^{2} \cdot$ Antonio J. Calleja-Rodríguez $^{2}$
}

Received: 10 December 2019 / Accepted: 12 August 2020 / Published online: 29 August 2020

(c) Springer-Verlag GmbH Germany, part of Springer Nature 2020

\begin{abstract}
The enormous inroads made by renewable energy in recent years have been the key to the development of new technologies designed to obtain energy from a range of resources. Hydrokinetic microturbines used to harness kinetic energy from rivers, tidal and marine currents epitomize such developments. As the reservoir is dispensed with, the water footprint normally associated with conventional hydroelectric generation is minimized. The new prototypes being developed require laboratories with water tunnel infrastructures where they can be accurately reproduced under controlled conditions. However, the construction of a water tunnel demands considerable investment, which prevents many research groups from completing their prototype design work. This paper charts the design of a low-cost hydrodynamic water tunnel at the University of Oviedo, indicating the mechanical and electronic elements as well as the software developments that make up the facility. This construction is a part of a research strategy focused on making the study of new hydrokinetic microturbines designs economically feasible. Moreover, it includes a description of a special software application used to perform the characterization of a hydrokinetic microturbine model in the water tunnel and a demonstration of the scope of the facility in the experimental study of a unit with a Darrieus rotor.
\end{abstract}

\section{Graphic abstract}

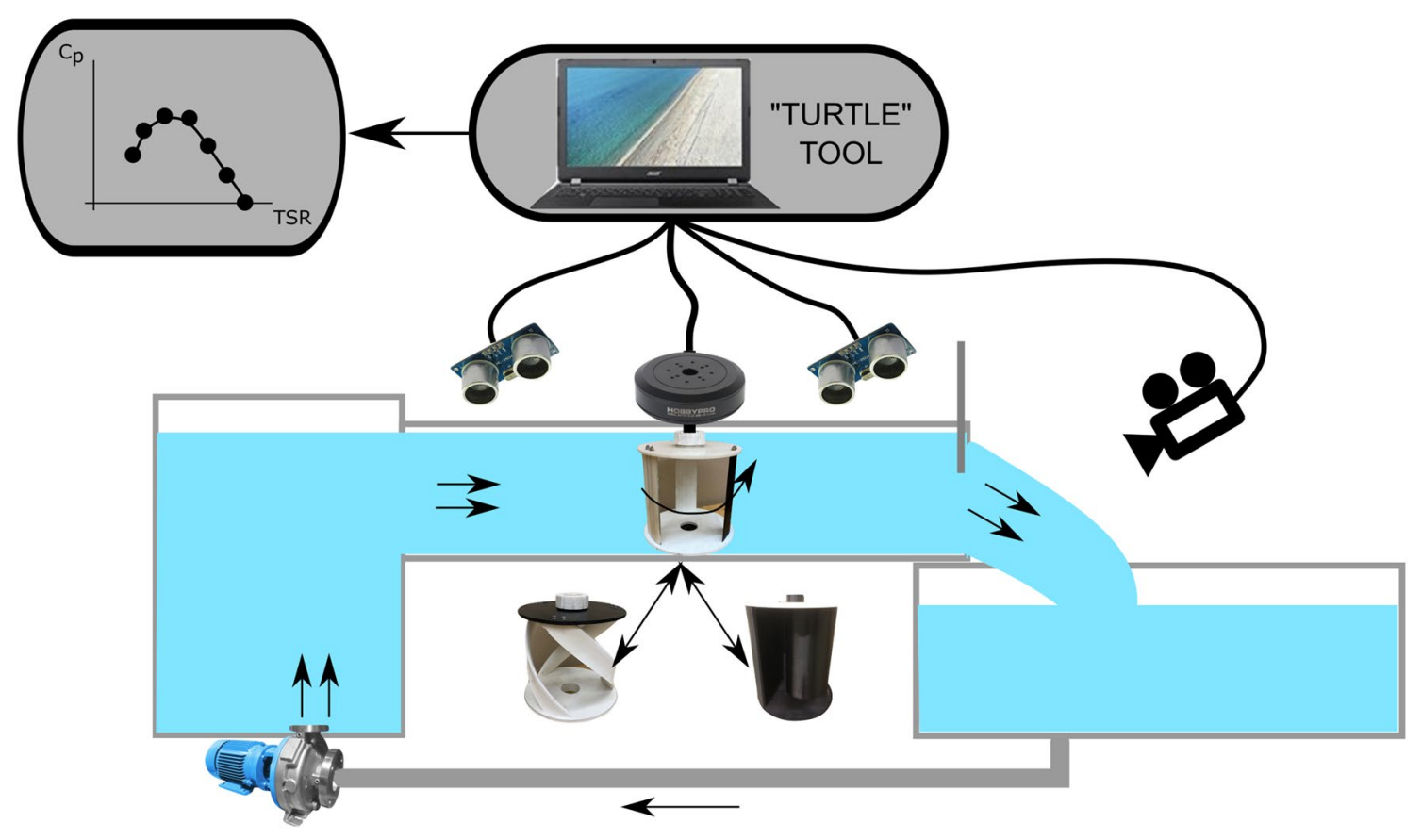

Extended author information available on the last page of the article 
Keywords Hydrodynamic water tunnel $\cdot$ Hydrokinetic microturbine $\cdot$ Power electronics $\cdot$ Permanent magnet generator (PMG)

\section{Introduction}

Hydropower generation is the largest renewable source worldwide, and despite seeing its installed capacity slow down in 2019 (12.7 GW in 2019), the production of hydropower soared to a record 4306 terawatt hours (TWh), which is the single largest contribution from a renewable energy source in history (IHA 2019). The outbreak of COVID-19 and its subsequent impact has demonstrated the resilience of the renewable sources (Earth.org) and their fundamental role in the future of electricity generation. In such a context, and despite the significant impact of the virus on the economy, the hydropower capacity is expected to increase in 2020 and rise further in 2021 (IEA 2020) thereby maximizing its share in the demand and supply of energy in the immediate future.

Most hydropower plants use a dam to store water in a reservoir, and electricity is produced by releasing water from that reservoir through a turbine which harnesses the energy of the water flow rate between the different levels created. These plants, although traditionally considered as sources of renewable energy, when constructed have a significant environmental impact which demands that any future plans for growth need careful consideration (Scherer and Pfister 2016).

One key factor to be considered is the water evaporation loss from the reservoir directly affecting the water cycle which can be quantified using the blue water footprint parameter, which for this specific case can be obtained by dividing the water evaporation by the energy production in a year (Mekonnen and Hoekstra 2012). Using this parameter, different studies indicate that reservoirs and therefore conventional hydroelectric plants are important water consumers. Mekonnen and Hoekstra 2012 calculate the blue water footprint of 35 taken from selected hydropower plants in a variety of places in the world (representing some $8 \%$ of the total installed capacity) concluding that the water evaporation was equivalent to the $10 \%$ of the one that corresponds to the global crop production in a year. Other studies show the importance of the water footprint in different locations, such as New Zealand (Herath et al. 2011) where most of the energy production is generated by hydropower, Romania (Robescu and Bondrea 2019) or China (Zhang et al. 2019).

The fact that hydrokinetic turbines located in rivers, ocean, or tidal currents are able to generate power from water currents without the necessity of a reservoir (Johnson and Pride 2010) opening the door to an alternative to sustainable exploitation of a significant mass of energy while minimizing the blue water footprint value and the necessity of important constructions considered ecologically negative. Only taking into account the marine currents (in the open sea or tidal currents), the potentially usable energy figures are noticeably high: The International Energy Agency (IEA) had estimated the global potential of ocean energy (which includes sources such as tidal, marine-current, osmotic, ocean-thermal and wave energy), to be as high as 20,000 TWh/y (IEA 2017).

The initial hydrokinetic prototypes were highly rated power $(>500 \mathrm{~kW})$ designs, need depth places for their installation therefore requiring important investments (supporting structures, wiring, etc.) and involving expensive operation and maintenance (O\&M) tasks (Laws and Epps 2016). Those conditions demand a significant number of operating hours to ensure the project's economic feasibility, which due to certain technical difficulties of the prototypes that have yet to be overcome impede their breakthrough to a commercial phase (Hooper and Austen 2013). Due to the aforementioned hindrances to development, the current research studies of hydrokinetic microturbines cite those devices as a cost-effective alternative, as they allow for the use of water currents in shallow water conditions (Mosbahi et al. 2020).

In recent years, research into new designs of hydrokinetic turbines has increased considerably. Two lines of work can be clearly distinguished. The distinction can be drawn when comparing the position of the axis of rotation versus the flow: axial-flow microturbines (the axis and flow are parallel) or cross-flow turbines (axis and flow are perpendicular) (dos Santos et al. 2019).

Axial-flow microturbine design is similar to that of wind flow turbines only with higher efficiencies than cross-flow ones. However, they are based on a complex mechanical system of a turbine rotor coupled with an electrical generator, both of which are submerged in an encapsulated setting. This complicated design involves elevated costs for prototype construction. Recent investigations in axial-flow microturbines have been theoretical or numerical studies focused on different research topics, but with barely any experimental validations, such as optimizing their electromechanical design by defining dynamic mathematical turbine models, connecting blocks corresponding to the hydrokinetic rotor mechanical production - using the blade element method (BEM) theory (Amarante Mesquita et al. 2014) or a CFD model (Moreno Vásquez et al. 2016) — with a multiplier and electric generator permanent magnet synchronous, studying how reducing the impact of solids in the flow affects their operation (Anyi and Kirke 2010), or the increase in the production of power generated by using a ducted rotor design (Wang et al. 2019). 
Cross-flow turbines are based mainly on Darrieus, Savonious or Gorlov rotors (Khan et al. 2009), with lower efficiencies than the axial-flow ones but employing a more straightforward electromechanical system, which simplify the design of prototypes and reduce the cost of their construction. Cross-flow microturbines can be horizontal or vertical axis. Vertical-axis microturbines are suitable for clustering in arrays, arranged perpendicular to the flow, and maximizing the area of energy extraction. Recent research using these cross-flow turbines has been theoretically or numerically based, and in some cases with experimental validations (thanks to their simple design which allows for model simulation) into two principal lines of research focused on: new designs which improve rotor efficiencies or evaluations of how the free-surface affects their performance. Examples of the first line are the new design of four-blade horizontal-axis Savonious rotor that includes a mechanical system with self-adjusting blades presented in Behrouzi et al. (2019), the vertical-axis Savonious (typical of two blades) optimization numerical CFD study performed in Kumar and Saini (2017), or the effect on the turbine performance of a diffuser coupled to a horizontal-axis Darrieus rotor described in Kirke (2011). An example of the second line of research pinpoints the numerical CFD study of the influence of the free-surface in the performance of a horizontal-axis Darrieus rotor offered by Benchikh Le Hocine et al. (2019).

In order to proceed to the experimental evaluation of microturbine designs, hydrodynamic water tunnels (HWT) are needed. These structures can simulate different water conditions and current velocities. Thus, a microturbine model's behavior can be calculated and extrapolated for different situations in a controlled environment and with a greater degree of precision.

Until now, there have been few HWT infrastructures in the world and the construction of a new one involves high investment which has significantly hindered any possible research into the field of hydrokinetic microturbines. The existing units belong to important Research Institutes or Universities with generous budgets, for example, the Emerson Cavitation Tunnel at Newcastle University (UK) (Atlar 2000) with a pumping system up to $300 \mathrm{~kW}$, in which a water velocity of $8 \mathrm{~m} / \mathrm{s}$ can be reached and where $400 \mathrm{~mm}$ high rotors can be adequately simulated.

Other examples of HWT facilities are those installed at the Canadian Hydrokinetic Turbine Test Centre (CHTTC) and the Science and Technology University of Missouri. The CHTTC can reach velocities of up to $1.1 \mathrm{~m} / \mathrm{s}$. One of the main characteristics is that this facility allows for the testing of vertical and horizontal turbines of up to $30 \mathrm{~cm}$ in height. The HWT located in Missouri (USA) is a compact channel in which velocities of up to $0.9 \mathrm{~m} / \mathrm{s}$ can be reached. In this case, the different prototypes are anchored to the channel deck by using a metallic rail. In this way, the turbine can be tested at different points lining the glass channel (Zhou 2012).

Taking into account the financial constraints that impede any furthering of research into hydrokinetic turbines, we (the investigators at Oviedo University, GIFD and ce3i2 groups) have outlined a research strategy designed to achieve new goals at relatively little cost (Fig. 1). The strategy comprehends three phases: (1) the design of a hydrokinetic microturbine, (2) the design and construction of a HWT to experimentally characterize different rotors coupled in the microturbine (previously created) hereafter referred to as "micro turbine models" and (3) to develop a methodology able to extrapolate the experimental results obtained in the HWT and apply it to real installation scenarios. In the first phase, a low-cost and simple design of a vertical-axis microturbine has been applied. In the second, a HWT has been built at the Mieres
Fig. 1 Research strategy general overview

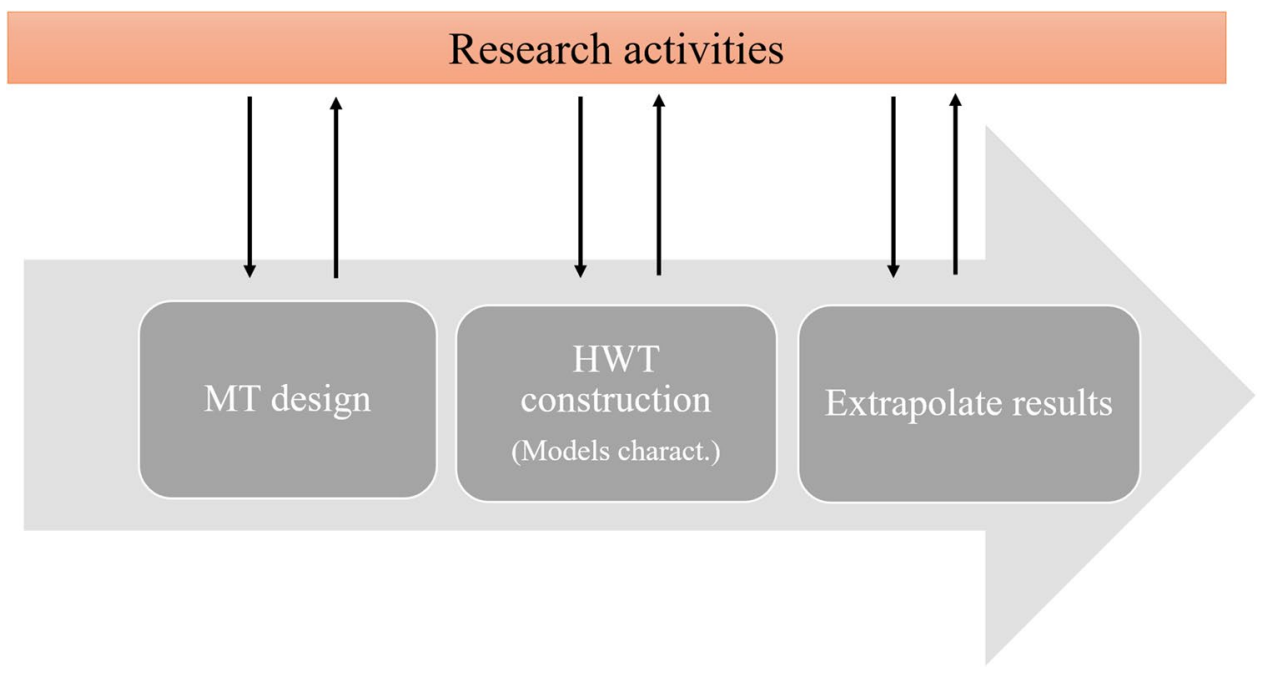


Polytechnic School (Mieres, Spain), specifically designed to study vertical-axis microturbines models.

This paper includes an explanation of the research strategy and a full description of the hydraulic and control elements of the HWT. It also pinpoints the results of the experimental tests of a microturbine model with a specific rotor in order to show how the whole set up works.

\section{Research strategy}

\section{Phase 1}

During the first phase, a vertical-axis hydrokinetic microturbine has been designed (Fig. 2). The design is based on low-cost components (rotor, generator and axis) which have helped simplify to a large degree the process of procurement of electrical power (Alvarez Alvarez et al. 2018). With this in mind, permanent magnet generators (PMG) (Chinchilla et al. 2006) have been selected to optimize the efficiency and cost of the electrical stages as well as to facilitate the implementation of control strategies. Using this previous design, a full range of rotors built using a 3D printer can be coupled up and tested.

\section{Phase 2}

In this phase, the HWT has been designed and built, including all the necessary equipment to perform the characterization tests of vertical-axis microturbine models corresponding to different rotors designs. Specifically, the HWT infrastructure includes a special software application known as the power coefficient application which helps provide the function of turbine efficiency or power coefficient against its tip-speed ratio (TSR) (1)—ratio between the tangential speed of the tips of the turbine blades and the water velocity - for different water conditions of water velocity and height. In order to acquire the variables of that function, the following expressions are used (Aghsaee and Markfort 2018),

$P_{\mathrm{h}}=\frac{1}{2} \rho A U^{3}$

$C_{\mathrm{p}}=P_{\mathrm{e}} / P_{\mathrm{h}}$

where $P_{\mathrm{e}}(\mathrm{W})$ is the electrical power produced, $P_{\mathrm{h}}(\mathrm{W})$ is the hydraulic power potential (maximum power that can be obtained from the flow); $\rho\left(\mathrm{kg} / \mathrm{m}^{3}\right)$ is the water density; $U$ $(\mathrm{m} / \mathrm{s})$ is the flow velocity upstream the turbine; $A\left(\mathrm{~m}^{2}\right)$ is the area swept by the rotor blades transverse to the water current; and $C_{\mathrm{p}}(1)$ is the turbine power coefficient (includes hydraulic, mechanical and electrical efficiencies).

And the TSR,

$\mathrm{TSR}=\frac{\omega R_{\mathrm{tur}}}{U}$

where $\omega(\mathrm{rad} / \mathrm{s})$ and $R_{\text {tur }}(\mathrm{m})$ are the rotational speed and the radius of the turbine rotor.

The function of $C_{\mathrm{p}}$ against TSR (Kumar and Sarkar 2016) is typical of each hydrokinetic turbine, with a maximum efficiency value called the maximum power point (MPP) (Abdeddaim and Betka 2013). To ensure a correct turbine operation at this maximum efficiency point within its own range of velocities (cut-in and cut-out velocities), a control strategy known as maximum power point tracking (MPPT) needs to be defined.

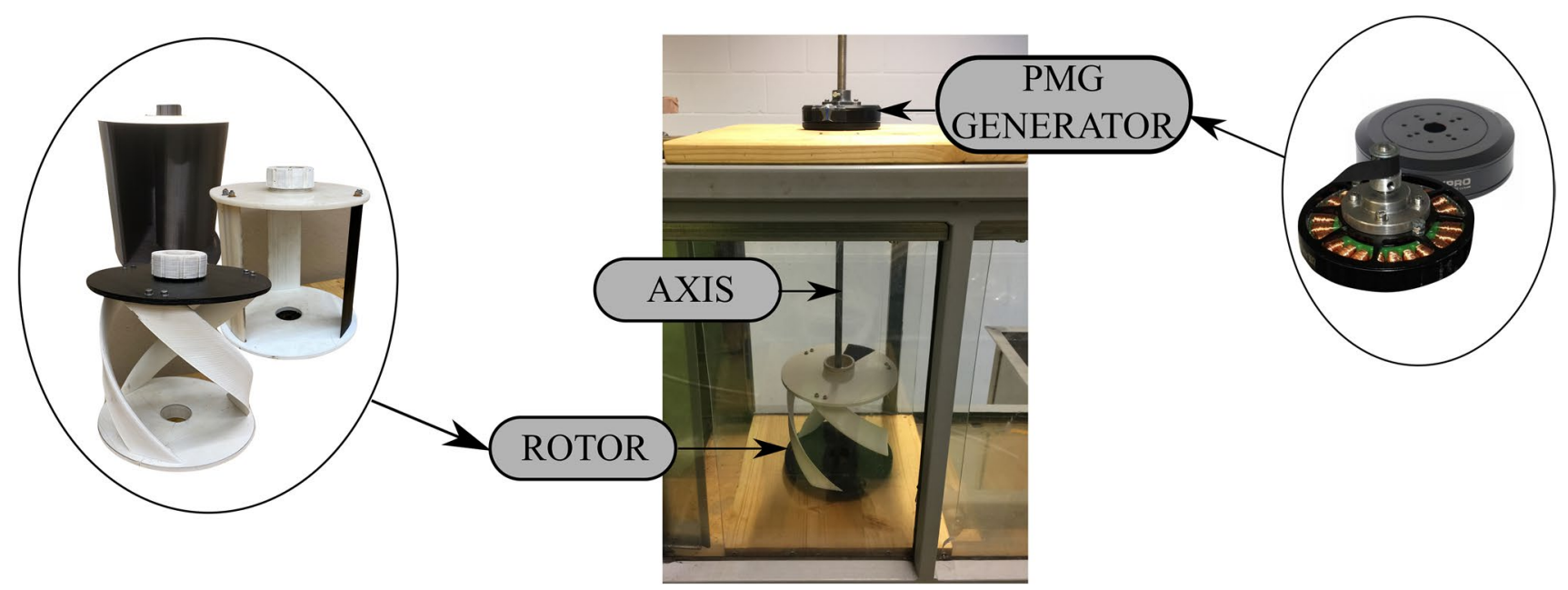

Fig. 2 Hydrokinetic microturbine (University of Oviedo design) 


\section{Phase 3}

The aim of this phase is to extrapolate the test results obtained in the second phase with a specific model in order to determine its performance on a larger scale in different installation scenarios, such as open waters or confined flow conditions. This phase will be more comprehensively outlined in future works.

\section{Tunnel description}

The design of the HWT is laid out in such a way as to observe the water movement made by two centrifugal electric pumps between two tanks and an intermediate glass channel where the rotor is tested. The water velocity is created by this movement, obtaining speeds of around $1 \mathrm{~m} / \mathrm{s}$ (low velocities). The HWT includes a hydraulic system and a control system known as TURbine Test Laboratory Equipment (TURTLE) (Fig. 3). The hydraulic system consists of a glass channel (C), a reassuring tank (T1) and a recirculation tank (T2), a pumping group (P) and a floodgate (F). The control system is made up of a supervisory control and data acquisition (SCADA) called TURTLE Tool as well as actuators and sensors.

The following section describes each of the elements of the HWT indicating those of own design.

\section{Hydraulic system}

The hydraulic system allows for the consolidation of a constant recirculation flow rate in the water channel where the model is tested. The water channel has a $0.5-\mathrm{m}$ high rectangular section, is $0.3 \mathrm{~m}$ wide and with a length of $1.5 \mathrm{~m}$ (Fig. 4). The whole channel is protected by transparent glass walls so that the different tests can be filmed. Incorporated within the channel is a rectangular stainless sliding floodgate to regulate the water flow.

Furthermore, to test different microturbine models, a plug and play system to connect different rotors based on a vertical axis and a set of bearings (radial and axial) (Fig. 4) has been constructed. On the upper level/section, a specifically designed piece has been built to attach the PMG.

Both pumps are centrifugal with a nominal flow rate of $300 \mathrm{~m}^{3} / \mathrm{h}$ and a power of $15 \mathrm{~kW}$ each, controlled by pump drive converters. The reassuring tank is rectangular, made of stainless steel, with a $1 \mathrm{~m}^{3}$ water capacity. The water enters through its lower part and has a set of baffle plates to eliminate water turbulences before entering the channel (Fig. 5).

The recirculation tank is also made of stainless steel and has a $4.8 \mathrm{~m}^{3}$ water capacity. Its main use is to collect the water that falls from the glass channel and feed the pumps to allow for re-circulation of the HWT.

\section{TURTLE system}

The HWT has been equipped with the TURTLE system which allows the user to control the volume of power extracted by the turbine, while managing and sustaining the channel flow conditions of water velocity upstream, the microturbine as well as the level of the water.

The TURTLE system (Fig. 6) includes the TURTLE Tool supervision software, installed in a PC bus-connected to the Turtle board, ultrasonic water height measurement system and pump drives converters; all of which are directly connected to both a commercial video camera and a flood gate pneumatic actuator. The TURTLE Tool, the Turtle board, as well as the ultrasonic water height measurement system are of our own design.
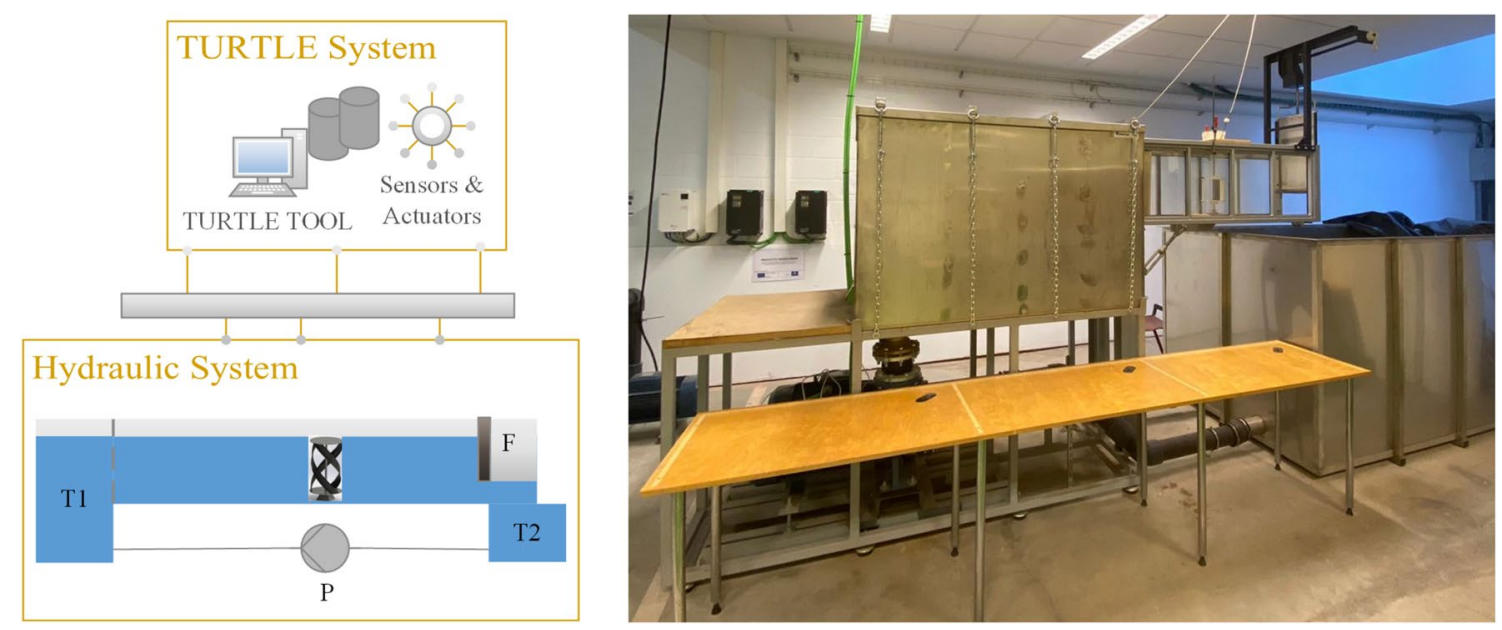

Fig. 3 HWT infrastructure 
Fig. 4 HWT glass channel

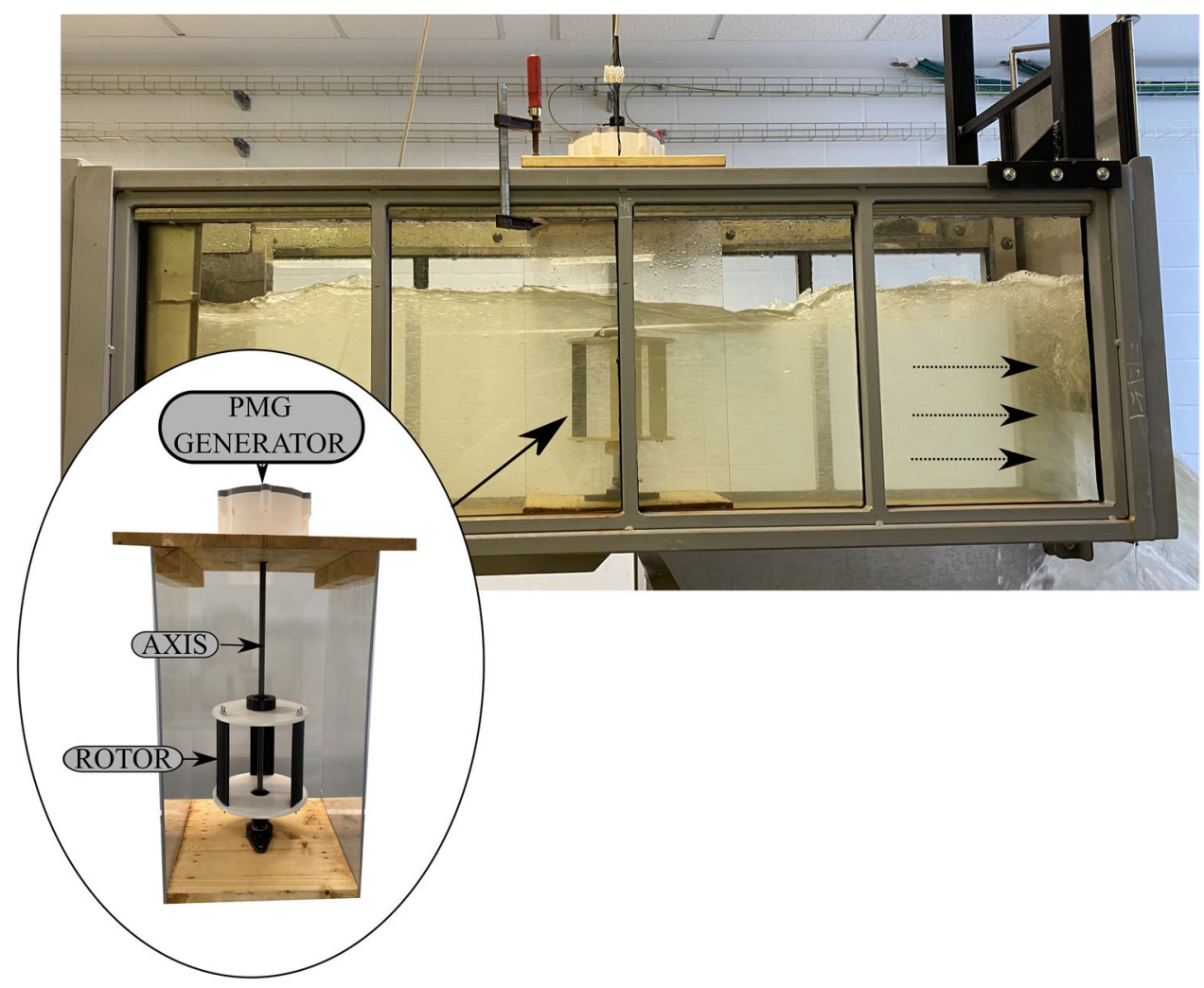

Fig. 5 Reassuring tank detail

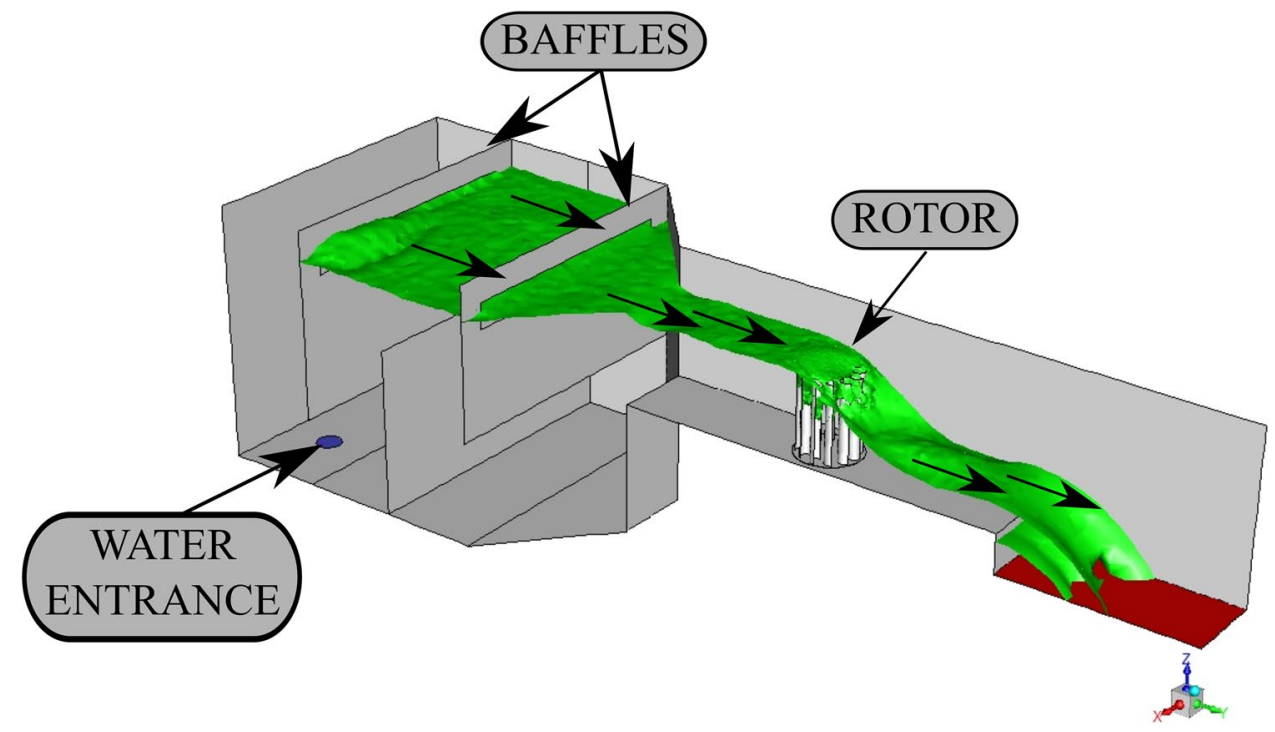

\section{TURTLE board}

The TURTLE board is made up of a series of electronic components (Fig. 7) that connect the PMG with a load resistance $\left(R_{\mathrm{LOAD}}\right)$ (rectifier, LC filter and high-frequency power converter) and measure both PMG electrical frequency and DC output voltage. The board also incorporates a control unit based on a microcontroller control unit (MCU) that performs a series of tasks through a specific software development: control of the turbine load, measurement of the electrical variables and all the while maintaining communication with the TURTLE Tool.

The rectifier and LC filter produce a DC voltage which is proportional to the turbine rotational speed. The MCU varies the turbine load by executing the duty cycle $(d)$ control on the high-frequency power converter which produces the 


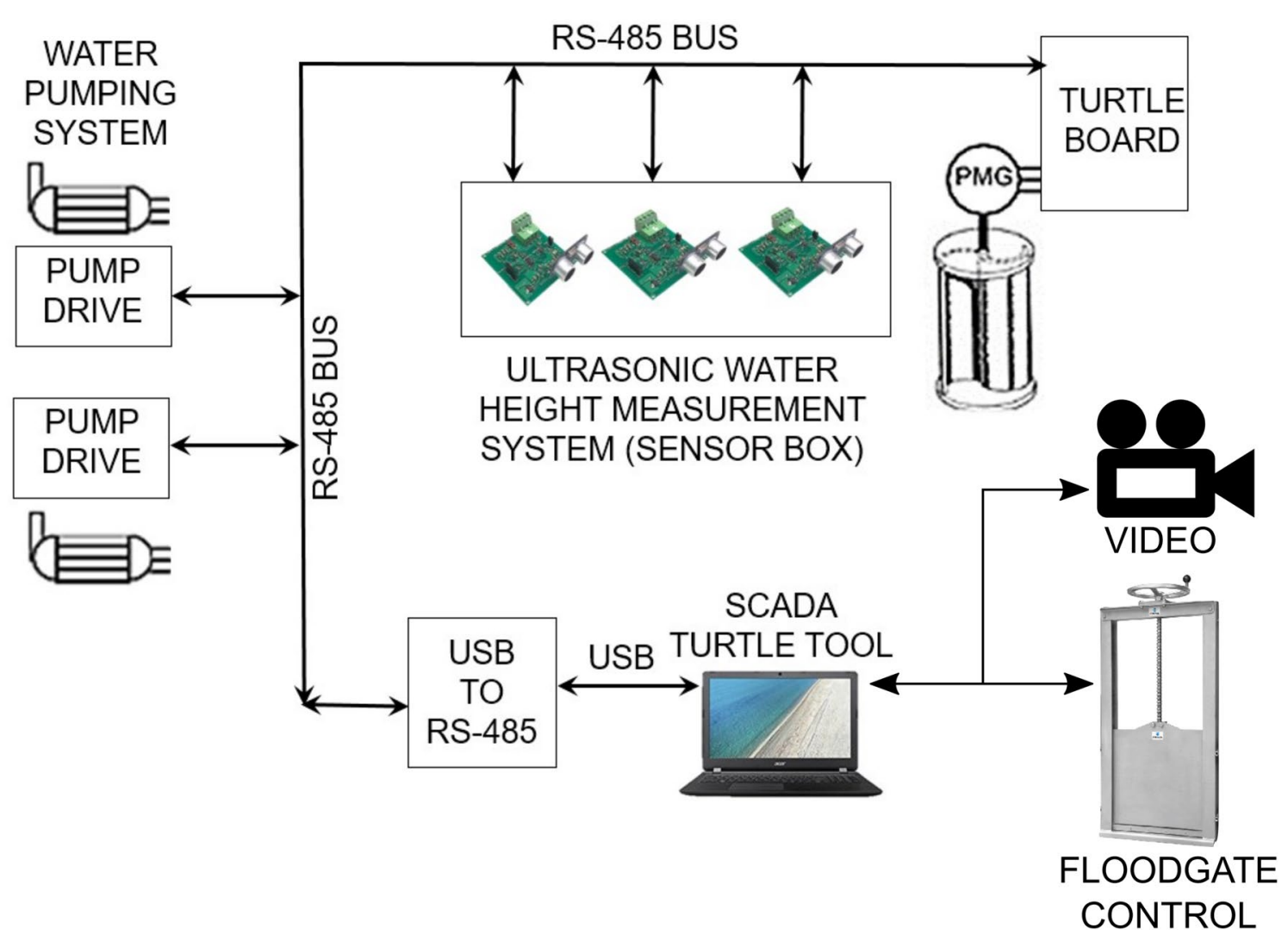

Fig. 6 Overview of TURTLE system

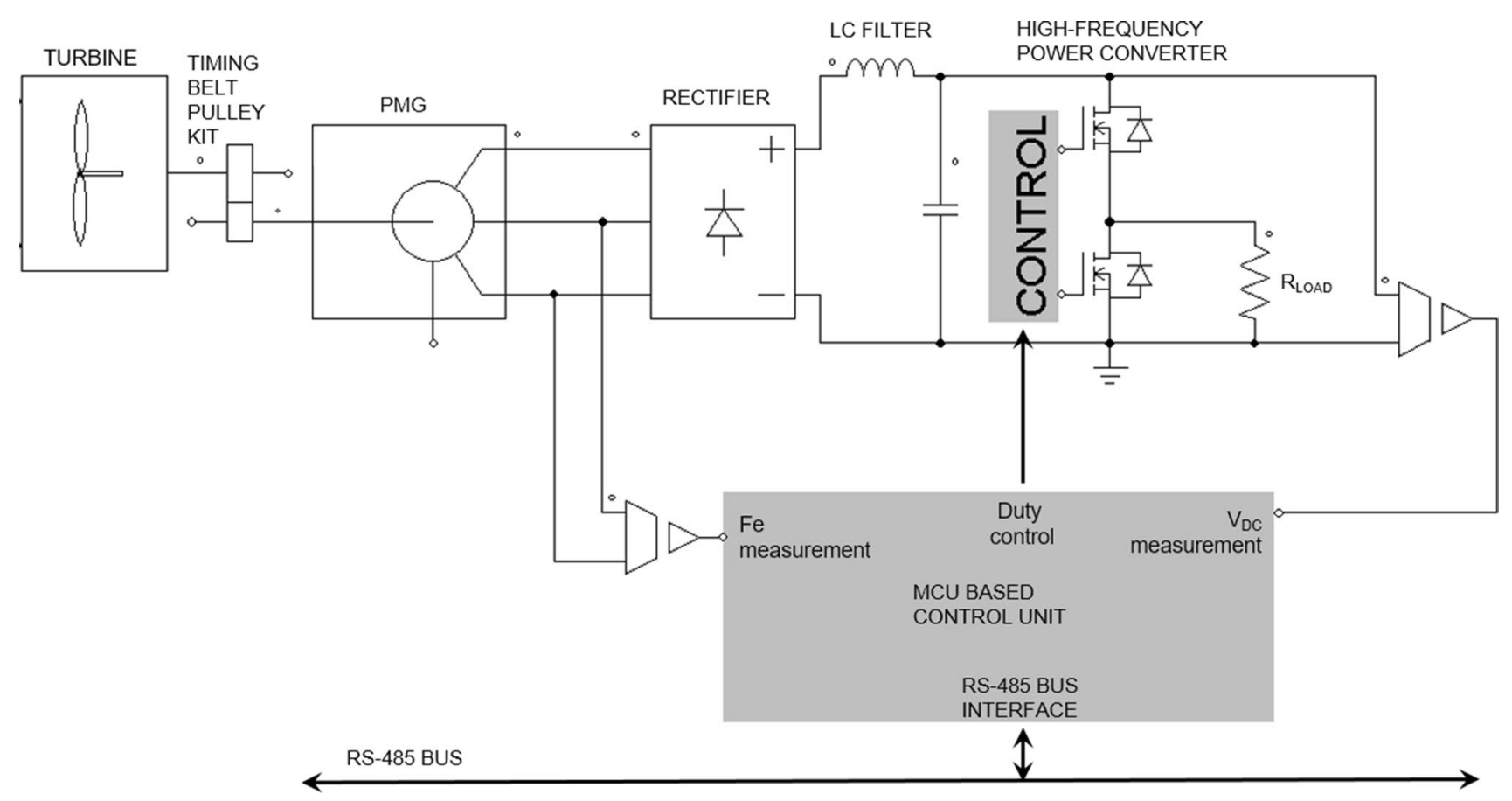

Fig. 7 TURTLE board components 
effect of a variation in the resistance. The electrical power $\left(P_{\mathrm{e}}\right)$ obtained is

$P_{\mathrm{e}}=\frac{v_{\mathrm{DC}}^{2}}{\left(R_{\mathrm{LOAD}} / d\right)}=\frac{v_{\mathrm{DC}}^{2}}{R_{\mathrm{LOAD}}} \cdot d$

where $v_{\mathrm{DC}}$ is the DC voltage $(\mathrm{V}), d(1)$ is the duty value varying between 0 and 1 and $R_{\mathrm{LOAD}}(\Omega)$ is the load resistance, adjusted depending on the turbine maximum power.

\section{Ultrasonic water height measurement system}

The ultrasonic water height measurement system (Fig. 8) consists of three sensor boards PIC16F1823 MCU from Microchip, fitted in a sensor box, each with an ultrasonic water height sensor (HC-SR04) and a temperature sensor (TC77). To improve accuracy, the boards have been placed in different positions all along the width of the channel.

\section{TURTLE tool}

The TURTLE Tool communicates with all sensors and actuators, performs calculations with data collected and is entrusted to execute the user interface.

The communication protocol of the connection bus is based on MODBUS frame over the bus RS-485. In the communication hierarchy, the TURTLE Tool is the master while the other connected elements of the system act as slaves.

The TURTLE Tool includes a user interface that allows the user to: a) visualize the data that is being collected in real time or as a result of various calculations and b) adjust the parameters necessary to perform turbine tests and export the experimental results to an external text file. Figure 9 shows an image of the TURTLE Tool user interface.

Variables measured and calculated are shown in Tables 1 and 2, respectively. Parameters adjusted by the user are shown in Table 3.

\section{Power coefficient application and experimental test}

The power coefficient application included in the TURTLE Tool software makes it possible to obtain the function of $C_{\mathrm{p}}$ against the TSR for each model tested. It is based on the continuous variation in the duty cycle and therefore varying the turbine load, from $d=0$ which is the no load condition (minimum torque and maximum rotational speed) to $d=1$ the maximum load condition (maximum torque and minimum rotational speed) keeping the upstream water speed at a steady level as well as the level of the water in the channel. Figure 10 illustrates the procedure followed to obtain the $C_{\mathrm{p}}$ versus TSR function.

As an example of the use of the HWT infrastructure, a specific model with a Darrieus rotor has been tested (Fig. 11). The rotor is $0.15 \mathrm{~m}$ high and $0.15 \mathrm{~m}$ in diameter with three NACA 00015 blades of 50-mm cord. It has been constructed by using a $3 \mathrm{D}$ printer with plastic material (acrylonitrile butadiene styrene, ABS).

Figure 12 illustrates the functions of $C_{\mathrm{p}}$ plotted against the TSR obtained for water velocities of 0.5 and $0.6 \mathrm{~m} / \mathrm{s}$ maintaining a steady water height at $0.45 \mathrm{~m}$. For a water velocity of $0.5 \mathrm{~m} / \mathrm{s}$, in no load condition $(d=0)$, the TSR reaches a value of 4.21 , while it increases up to 4.53 for $0.6 \mathrm{~m} / \mathrm{s}$, also $C_{\mathrm{p}}$ values are higher with $0.6 \mathrm{~m} / \mathrm{s}$ than with

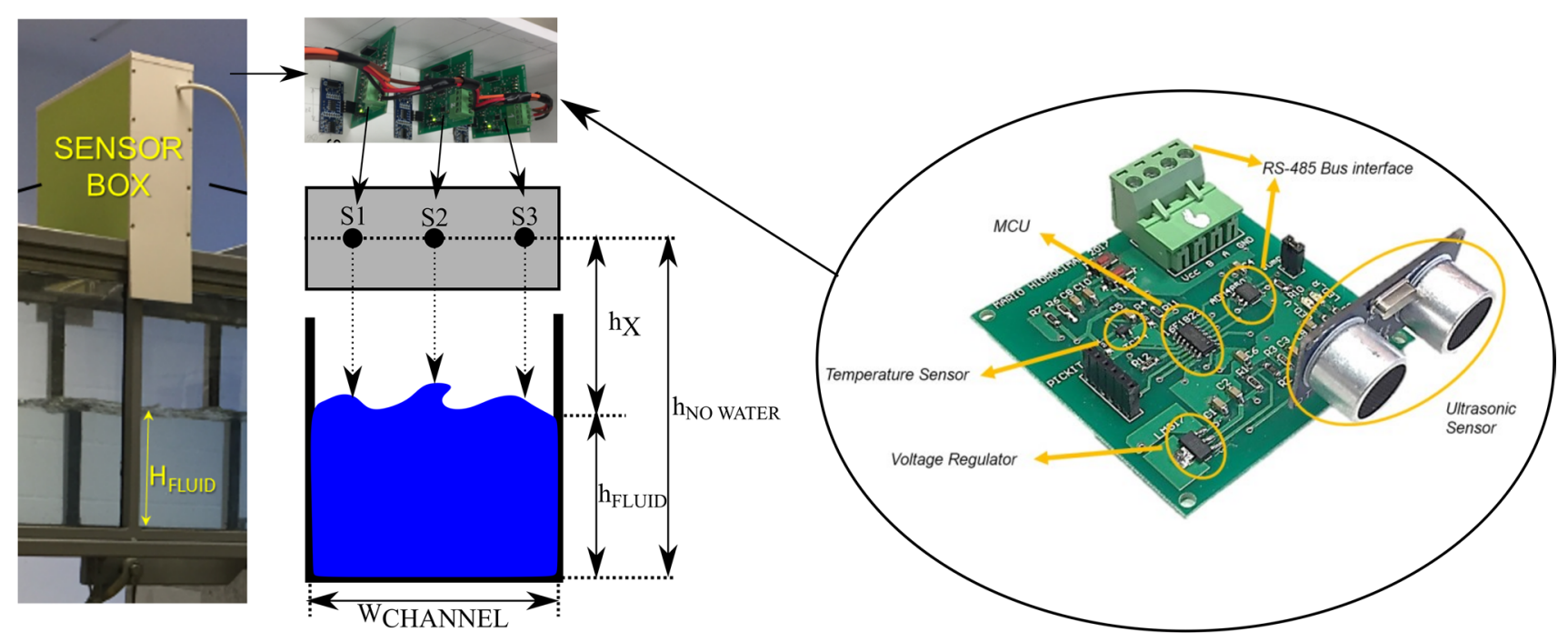

Fig. 8 Ultrasonic water height measurement sensor 


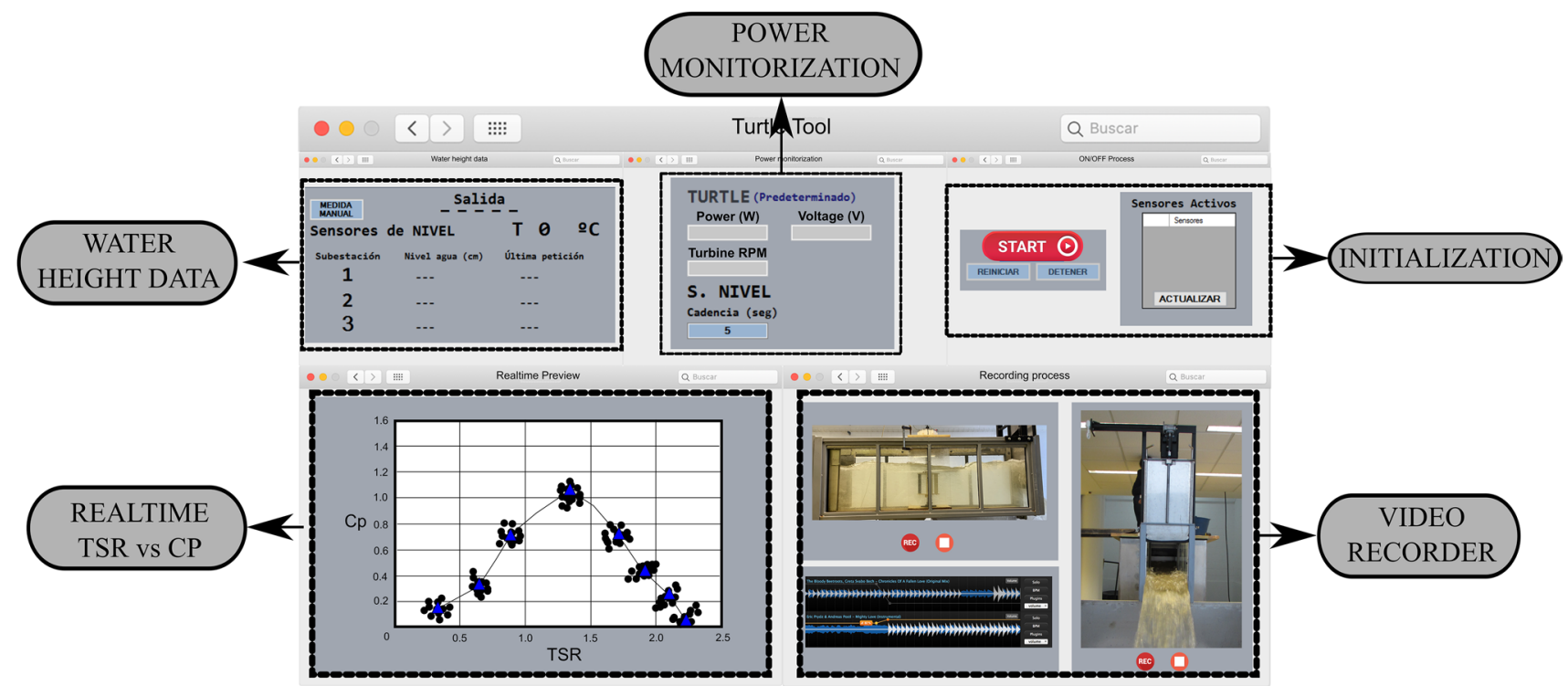

Fig. 9 TURTLE Tool user interface

Table 1 Measured variables

\begin{tabular}{llll}
\hline Variable & Description & Sensor & Units \\
\hline$V_{\mathrm{DC}}$ & DC voltage output value & TURTLE board & Volt $(\mathrm{V})$ \\
$F_{\mathrm{e}}$ & PMG electrical frequency & TURTLE board & Hertz $(\mathrm{Hz})$ \\
$h$ & Water height & Water height measurement sensor box & Meter $(\mathrm{m})$ \\
$T$ & Room temperature & Water height measurement sensor box & Degree Celsius $\left({ }^{\circ} \mathrm{C}\right)$ \\
$Q$ & Water flow rate & Pump drives & Meter cubic per second $\left(\mathrm{m}^{3} / \mathrm{s}\right)$ \\
\hline
\end{tabular}

Table 2 Calculated variables

\begin{tabular}{llll}
\hline Variable & Description & Calculation & Units \\
\hline$U$ & Water velocity & $U=\frac{Q}{0.3 h}$ & Meter per second (m/s) \\
$\omega$ & Turbine rotational speed & $\omega=\frac{2 \pi \cdot F_{\mathrm{e}}}{\mathrm{pp}}$ & Radian per second (rad/s) \\
$\mathrm{TSR}$ & Tip speed ratio & $\mathrm{TSR}=\frac{\omega R_{\mathrm{tur}}}{v}$ & Dimensionless (1) \\
$P_{\mathrm{h}}$ & Hydraulic power & $P_{\mathrm{h}}=\frac{1}{2} \rho A v^{3}$ & Watt (W) \\
$P_{\mathrm{e}}$ & Electrical power & $P_{\mathrm{e}}=\left(\frac{v_{\mathrm{DC}}^{2}}{R_{\mathrm{LOAD}}} d\right)$ & Watt $(\mathrm{W})$ \\
$C_{\mathrm{p}}$ & Power coefficient & $C_{\mathrm{p}}=\frac{P_{\mathrm{e}}}{P_{\mathrm{h}}}$ & Dimensionless (1) \\
\hline
\end{tabular}

$0.5 \mathrm{~m} / \mathrm{s}$ for any TSR. In both functions, increasing the $d$ value (and therefore the turbine torque) involves reducing the TSR value due to the decrease in rotational speed, while the $C_{\mathrm{p}}$ values increase until reaching a point of maximum efficiency (maximum $C_{\mathrm{p}}$ ). The maximum $C_{\mathrm{p}}$ values are 0.34 and 0.3 for the velocities of 0.6 and 0.5 , respectively. This maximum point is of particular interest as the control strategy of the turbine operation must ensure that it operates in those conditions continuously. From that point, the turbine enters in a zone of unstable performance and finally it stops. This behavior is typical of rotors moved by lift forces. This unstable zone should be avoided for strategies aimed at continuously striving to reach the maximum level of efficiency.

Having obtained these functions ( $C_{\mathrm{p}}$ against TSR) inside the tunnel, the new ones corresponding to the turbine located in open waters can be assessed. Each one corresponds to a water velocity in the free stream that is calculated from the water tunnel velocity by using the expressions proposed by Werle (Werle 2010), 
Table 3 Parameters

\begin{tabular}{lll}
\hline Parameter & Description & Units \\
\hline $\mathrm{pp}$ & PMG number of poles & Dimensionless (1) \\
$\rho$ & Water density & $\begin{array}{l}\text { Kilogram per } \\
\text { cubic meter }(\mathrm{kg} /\end{array}$ \\
& & $\begin{array}{c}3 \\
3\end{array}$ \\
$R_{\text {tur }}$ & Turbine radius & Meter $(\mathrm{m})$ \\
$A$ & $\begin{array}{l}\text { Section swept by the blades trans- } \\
\text { verse to the water current }\end{array}$ & Square meter $\left(\mathrm{m}^{2}\right)$ \\
$R_{\text {LOAD }}$ & $\begin{array}{c}\text { Resistance connected to TURTLE } \\
\text { board }\end{array}$ & Ohm $(\Omega)$ \\
$d$ & Duty adjustment & Dimensionless (1) \\
\hline
\end{tabular}

$U / U_{\mathrm{F}}=1-\mathrm{BR}$

where $U_{\mathrm{F}}(\mathrm{m} / \mathrm{s})$ is the free stream velocity, $U(\mathrm{~m} / \mathrm{s})$ is the velocity measured in the channel and BR (1) is blockage ratio obtained dividing the cross-sectional area of turbine in flow stream by the transversal channel section.

The new function values are obtained with (Bahaj et al. 2007),

$C_{\mathrm{pF}}=C_{\mathrm{p}}\left(U / U_{\mathrm{F}}\right)^{3}$

$\operatorname{TSR}_{\mathrm{F}}=\operatorname{TSR}\left(U / U_{\mathrm{F}}\right)$

where $C_{\mathrm{pF}}(1)$ and $\operatorname{TSR}_{\mathrm{F}}(1)$ are the new free stream values corresponding to the free stream velocity $U_{\mathrm{F}}(\mathrm{m} / \mathrm{s})$.

For this specific case, under scrutiny $\mathrm{BR}=0.17$ and thus the free stream velocities of 0.6 and $0.72 \mathrm{~m} / \mathrm{s}$ are those corresponding to 0.5 and $0.6 \mathrm{~m} / \mathrm{s}$ measured in the channel. The results with the new functions are shown in Fig. 13.

New functions with no blockage tend to overlap with maximum power coefficient values of 0.20 and 0.17 for free stream velocities of 0.72 and $0.6 \mathrm{~m} / \mathrm{s}$, respectively. These results are consistent with those of the experimental investigation presented in Patel et al. (2017) in which for a similar turbine rotor (Darrieus rotor with three NACA 0015 blades) a maximum power coefficient value of 0.16 is obtained for a free stream velocity of $0.46 \mathrm{~m} / \mathrm{s}$.

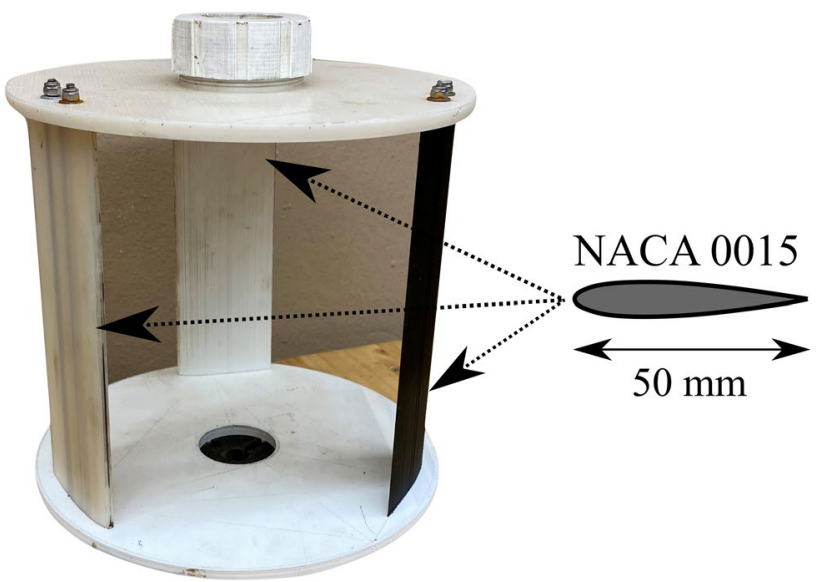

Fig. 11 Rotor design tested

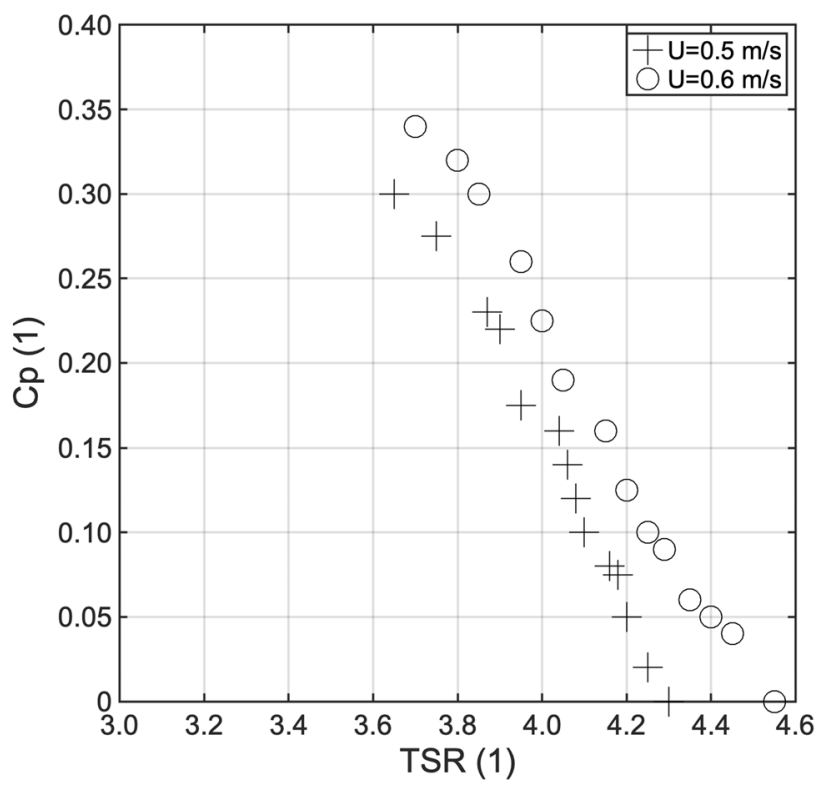

Fig. $12 C_{\mathrm{p}}$ (1) versus TSR (1) function
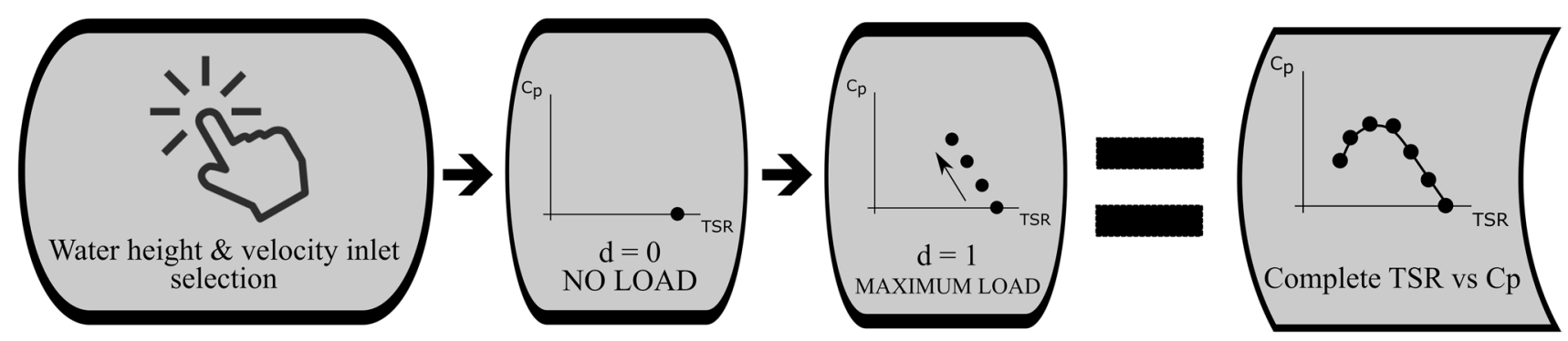

Fig. 10 Power coefficient application scheme 


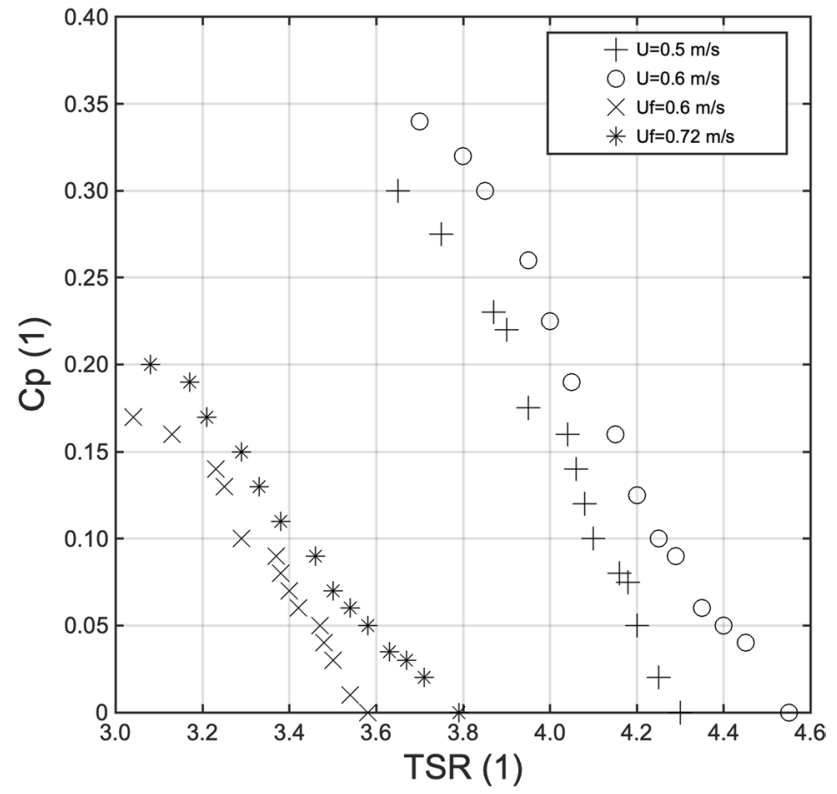

Fig. $13 C_{\mathrm{p}}$ (1) versus TSR (1) function (comparison with open waters characteristic)

\section{Conclusions}

The hydrokinetic water turbines are a sustainable alternative to the traditional hydroelectric power plant. With the aim of developing new investigations, a hydrodynamic water tunnel, built at the Mieres Polytechnic School, and specially designed to test hydrokinetic microturbines, has been outlined and proposed. This framework is made up of low-cost mechanic and electronic devices further bolstered by the latest developments in software. Its construction is the second phase of a three-phase strategy based on making it feasible to investigate in forthcoming hydrokinetic microturbine designs. It is adapted to characterize different verticalaxis microturbine models through experiments, which correspond to different rotors coupled in a microturbine device obtained in the first phase.

There is a series of original developments for this application such as the hydraulic system (channel and re-circulating system and mechanical devices prepared to test different turbine rotors) and the TURTLE control system which includes a supervision software called TURTLE Tool connected to different sensors and actuators, some of which have been designed by our team (TURTLE board and the ultrasonic water height measurement system). The TURTLE Tool also contains a specific software application that offers the user the opportunity to automatically obtain the microturbine function of power coefficient against tip-speed ratio. A model has been characterized as an example. The results conclusively demonstrate the degree to which water velocity can influence the efficiency of the turbine located both in the channel as well as in open water locations. It also earmarks the differences in the turbine's behavior when depending on the tip speed ratio.

\section{References}

Abdeddaim S, Betka A (2013) Optimal tracking and robust power control of the DFIG wind turbine. Int J Electr Power Energy Syst 49:234-242. https://doi.org/10.1016/j.ijepes.2012.12.014

Aghsaee P, Markfort CD (2018) Effects of flow depth variations on the wake recovery behind a horizontal-axis hydrokinetic in-stream turbine. Renew Energy 125:620-629. https://doi.org/10.1016/j. renene.2018.02.137

Alvarez Alvarez E, Rico-Secades M, Corominas EL et al (2018) Design and control strategies for a modular hydro kinetic smart grid. Int $\mathbf{J}$ Electr Power Energy Syst 95:137-145. https://doi.org/10.1016/j. ijepes.2017.08.019

Amarante Mesquita AL, Amarante Mesquita AL, Palheta FC et al (2014) A methodology for the transient behavior of horizontal axis hydrokinetic turbines. Energy Convers Manag 87:1261-1268. https://doi.org/10.1016/j.enconman.2014.06.018

Anyi M, Kirke B (2010) Evaluation of small axial flow hydrokinetic turbines for remote communities. Energy Sustain Dev 14:110 116. https://doi.org/10.1016/j.esd.2010.02.003

Atlar M (2000) A history of the Emerson cavitation tunnel. In: International conference on propeller cavitation, (NCT'50), pp 3-34

Bahaj AS, Molland AF, Chaplin JR, Batten WMJ (2007) Power and thrust measurements of marine current turbines under various hydrodynamic flow conditions in a cavitation tunnel and a towing tank. Renew Energy 32:407-426. https://doi.org/10.1016/j. renene.2006.01.012

Behrouzi F, Nakisa M, Maimun A et al (2019) Performance investigation of self-adjusting blades turbine through experimental study. Energy Convers Manag 181:178-188. https://doi.org/10.1016/j. enconman.2018.11.066

Benchikh Le Hocine AE, Jay Lacey RW, Poncet S (2019) Multiphase modeling of the free surface flow through a Darrieus horizontal axis shallow-water turbine. Renew Energy 143:1890-1901. https ://doi.org/10.1016/j.renene.2019.06.010

Chinchilla M, Arnaltes S, Burgos JC (2006) Control of permanentmagnet generators applied to variable-speed wind-energy systems connected to the grid. IEEE Trans Energy Convers 21:130-135. https://doi.org/10.1109/TEC.2005.853735

dos Santos IFS, Camacho RGR, Tiago Filho GL et al (2019) Energy potential and economic analysis of hydrokinetic turbines implementation in rivers: an approach using numerical predictions (CFD) and experimental data. Renew Energy 143:648-662. https ://doi.org/10.1016/j.renene.2019.05.018

Earth.org Why COVID-19 is creating a surge in demand for renewable energy. https://earth.org/covid-19-creating-a-surge-in-renewableenergy/. Accessed 7 Aug 2020

Herath I, Deurer M, Horne D et al (2011) The water footprint of hydroelectricity: a methodological comparison from a case study in New Zealand. J Clean Prod 19:1582-1589. https://doi. org/10.1016/j.jclepro.2011.05.007

Hooper T, Austen M (2013) Tidal barrages in the UK: ecological and social impacts, potential mitigation, and tools to support barrage planning. Renew Sustain Energy Rev 23:289-298. https://doi. org/10.1016/j.rser.2013.03.001

IEA IEA (2017) Key world energy statistics

IEA (2020) Renewable energy market update. OECD

IHA (2019) Hydropower Status Report 2018. Int Hydropower Assoc. https://doi.org/10.1103/PhysRevLett.111.027403 
Johnson JB, Pride DJ (2010) River, tidal and ocean current hydrokinetic energy technologies: status and future opportunities in Alaska, p 32

Khan MJ, Bhuyan G, Iqbal MT, Quaicoe JE (2009) Hydrokinetic energy conversion systems and assessment of horizontal and vertical axis turbines for river and tidal applications: a technology status review. Appl Energy 86:1823-1835. https://doi.org/10.1016/j. apenergy.2009.02.017

Kirke BK (2011) Tests on ducted and bare helical and straight blade Darrieus hydrokinetic turbines. Renew Energy 36:3013-3022. https://doi.org/10.1016/j.renene.2011.03.036

Kumar A, Saini RP (2017) Performance analysis of a single stage modified Savonius hydrokinetic turbine having twisted blades. Renew Energy 113:461-478. https://doi.org/10.1016/j.renen e. 2017.06.020

Kumar D, Sarkar S (2016) A review on the technology, performance, design optimization, reliability, techno-economics and environmental impacts of hydrokinetic energy conversion systems. Renew Sustain Energy Rev 58:796-813. https://doi.org/10.1016/j. rser.2015.12.247

Laws ND, Epps BP (2016) Hydrokinetic energy conversion: technology, research, and outlook. Renew Sustain Energy Rev 57:12451259. https://doi.org/10.1016/j.rser.2015.12.189

Mekonnen MM, Hoekstra AY (2012) The blue water footprint of electricity from hydropower. Hydrol Earth Syst Sci 16:179-187. https ://doi.org/10.5194/hess-16-179-2012

Moreno Vásquez FA, De Oliveira TF, Brasil Junior ACP (2016) On the electromechanical behavior of hydrokinetic turbines. Energy Convers Manag 115:60-70. https://doi.org/10.1016/j.encon man.2016.02.039

Mosbahi M, Ayadi A, Chouaibi Y et al (2020) Performance improvement of a novel combined water turbine. Energy Convers Manag 205:112473. https://doi.org/10.1016/j.enconman.2020.112473

\section{Affiliations}

\section{Eduardo Álvarez-Álvarez ${ }^{1}\left[\right.$ - Manuel Rico-Secades ${ }^{2} \cdot$ Aitor Fernández-Jiménez $^{1} \cdot$ Rodolfo Espina-Valdés $^{1}$. E. L. Corominas ${ }^{2} \cdot$ Antonio J. Calleja-Rodríguez $^{2}$}

Eduardo Álvarez-Álvarez

edualvarez@uniovi.es

Hydraulic R\&D Group - EP Mieres, University of Oviedo, Mieres, Spain
Patel V, Eldho TI, Prabhu SV (2017) Experimental investigations on Darrieus straight blade turbine for tidal current application and parametric optimization for hydro farm arrangement. Int J Mar Energy. https://doi.org/10.1016/j.ijome.2017.01.007

Robescu LD, Bondrea DA (2019) The water footprint from hydroelectricity: a case study for a hydropower plant in Romania. E3S Web Conf 85:1-7. https://doi.org/10.1051/e3sconf/20198506012

Scherer L, Pfister S (2016) Global water footprint assessment of hydropower. Renew Energy 99:711-720. https://doi.org/10.1016/j.renen e.2016.07.021

Wang WQ, Song K, Yan Y (2019) Influence of interaction between the diffuser and rotor on energy harvesting performance of a microdiffuser-augmented hydrokinetic turbine. Ocean Eng. https://doi. org/10.1016/j.oceaneng.2019.106293

Werle MJ (2010) Wind turbine wall-blockage performance corrections. J Propuls Power. https://doi.org/10.2514/1.44602

Zhang J, Lei X, Chen B, Song Y (2019) Analysis of blue water footprint of hydropower considering allocation coefficients for multipurpose reservoirs. Energy 188:116086. https://doi.org/10.1016/j. energy.2019.116086

Zhou H (2012) Maximum power point tracking control of hydrokinetic turbine and low-speed high-thrust permanent magnet generator design. Master Thesis 298:1-97

Publisher's Note Springer Nature remains neutral with regard to jurisdictional claims in published maps and institutional affiliations. 